\title{
Recent Trends in Cyclic Peptides as Therapeutic Agents and Biochemical Tools
}

\author{
Joon-Seok Choi and Sang Hoon Joo* \\ College of Pharmacy, Daegu Catholic University, Gyeongsan 38430, Republic of Korea
}

\begin{abstract}
Notable progress has been made in the therapeutic and research applications of cyclic peptides since our previous review. New drugs based on cyclic peptides are entering the market, such as plecanatide, a cyclic peptide approved by the United States Food and Drug Administration in 2017 for the treatment of chronic idiopathic constipation. In this review, we discuss recent developments in stapled peptides, prepared with the use of chemical linkers, and bicyclic/tricyclic peptides with more than two rings. These have widespread applications for clinical and research purposes: imaging, diagnostics, improvement of oral absorption, enzyme inhibition, development of receptor agonist/antagonist, and the modulation of protein-protein interaction or protein-RNA interaction. Many cyclic peptides are expected to emerge as therapeutics and biochemical tools.
\end{abstract}

Key Words: Cyclic peptides, Stapled peptides, Drug lead, Bicyclic peptide

\section{INTRODUCTION}

There are many biologically active peptides, natural or synthetic, with cyclic ring structure. The ring structure can be formed by linking one end to another, by a variety of chemical bonds, including amide, lactone, ether, thioether, and disulfide. Amide bond formation between amino and carboxyl termini results in the formation of a head-to-tail (or N-to-C) cyclic peptide. Many $\mathrm{N}$-to- $\mathrm{C}$ cyclic peptides with biological activity exist in nature. In the case of true $\mathrm{N}$-to-C cyclic peptides, there is just one possible cyclization between amino and carboxyl termini and the ring structure is straightforward. If not an N-to$\mathrm{C}$ cyclic peptide, the ring structure can be more varied allowing bicyclic and tricyclic peptides to exist. For example, human guanylin (Fig. 1) has four cysteine residues, all of which form two intramolecular disulfide linkages resulting in a bicyclic peptide (Lauber et al., 2003). Cyclic peptides have several beneficial properties unlike their linear counterparts. Firstly, the rigidity of cyclic peptides increases binding affinity and selectivity toward target molecules, due to a decreased entropy term in the Gibbs free energy equation (Edman, 1959; Horton et al., 2002). Secondly, cyclic peptides are resistant to hydrolysis by exopeptidase as they lack amino and carboxyl ends. Cyclic peptides can even be resistant to endopeptidases if the rigid ring structure prevents endopeptidase from accessing the cleavage site. Thirdly, some cyclic peptides show better membrane permeability and can cross the cell membrane (Kwon and Kodadek, 2007). Cyclosporine, an immunosuppressant, is a good example of a cyclic peptide with membrane permeability. These three properties can allow cyclic peptides to be better drug-like molecules than their linear counterparts.

In this review, we present recent progress in the field of cyclic peptides, including stapled peptides and bicyclic/tricyclic peptides. Novel applications of cyclic peptides are reported in imaging, diagnostics, improvement of oral absorption, enzyme inhibition, development of receptor agonist/antagonist, and the modulation of protein-protein interaction and proteinRNA interaction.

\section{RECENT DEVELOPMENTS IN THE PREPARATION OF CYCLIC PEPTIDES}

Cyclic peptide compounds have been developed through several approaches: phage display technology, split-intein circuit ligation of peptides and proteins (SICLOPPS), mRNA display, combinatorial chemistry, as well as de novo synthesis (Joo, 2012). We have observed noticeable improvements in the way cyclic peptides (stapled cyclic peptides and bicyclic/ tricyclic peptides) are prepared.

\section{Open Access https://doi.org/10.4062/biomolther.2019.082}

This is an Open Access article distributed under the terms of the Creative Commons Attribution Non-Commercial License (http://creativecommons.org/licenses/by-nc/4.0/) which permits unrestricted non-commercial use, distribution, and reproduction in any medium, provided the original work is properly cited.
Received May 17, 2019 Revised Aug 9, 2019 Accepted Aug 12, 2019

Published Online Oct 10, 2019

\section{*Corresponding Author}

E-mail: sjoo@cu.ac.kr

Tel: +82-53-850-3614, Fax: +82-53-359-6729 
A

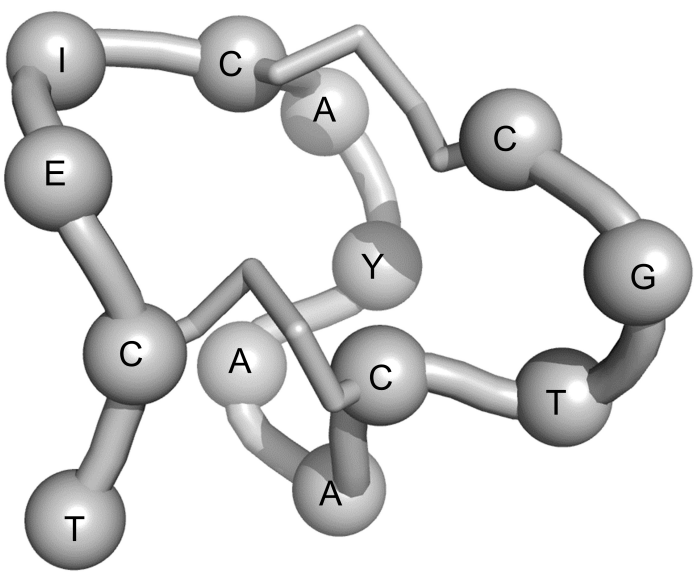

B

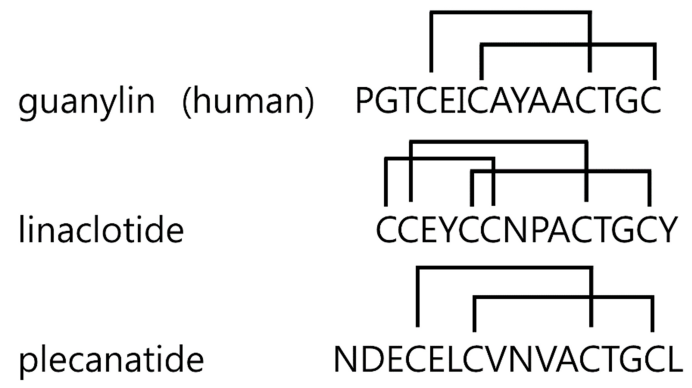

Fig. 1. Structure of guanylin. (A) Solution structure of guanylin. Alpha carbons are shown as spheres, and the disulfide bonds are shown as sticks. The model was drawn from PDB id 1gnb. (B) Amino acid sequences of guanylin and its analogs linaclotide and plecanatide. Disulfide bonds are indicated.

Stapled peptides are an emerging type of cyclic peptides (Fairlie and Dantas de Araujo, 2016). The concept of "stapling" itself is not new, and refers to the connection of two parts of a molecule using a cross-linker (Walensky et al., 2004). The term tends to be used to indicate any cyclic peptides that are not N-to-C cyclic peptides. The cross-linker for stapling can be varied to improve physicochemical properties, and several cross-linking methods are available, including disulfide formation, olefin, cysteine-alkylation, and biaryl crosslinking. By varying the length, rigidity, and hydrophobicity of a cyclization linker, Lin and colleagues optimized a dengue virus NS2B/ NS3 protease inhibitor (Lin et al., 2017).

The use of cross-linkers extends to cyclic peptides based on phage display, allowing the formation of bicyclic peptides. The original cyclic peptides based on phage display were introduced in early 1990's. The peptide sequence -Cys- $X^{1}-X^{2}-$ $X^{3}-X^{4}-X^{5}-X^{6}-C y s-$ displayed on the coat protein of a phage particle forms a cyclic peptide in which two cysteine residues form a disulfide bond. A cyclic peptide with platelet glycoprotein binding activity could be screened from a library (O'Neil et al., 1992). While phage display is limited to natural, ribosomal amino acids, the diversity of the phage display method $\left(\sim 10^{9}\right.$ different sequences) makes it an attractive approach to search for cyclic peptides with affinity toward target molecules. While the initial approach was limited to mono-cyclic peptides, bicyclic peptides can now be prepared by phage display. In theory,
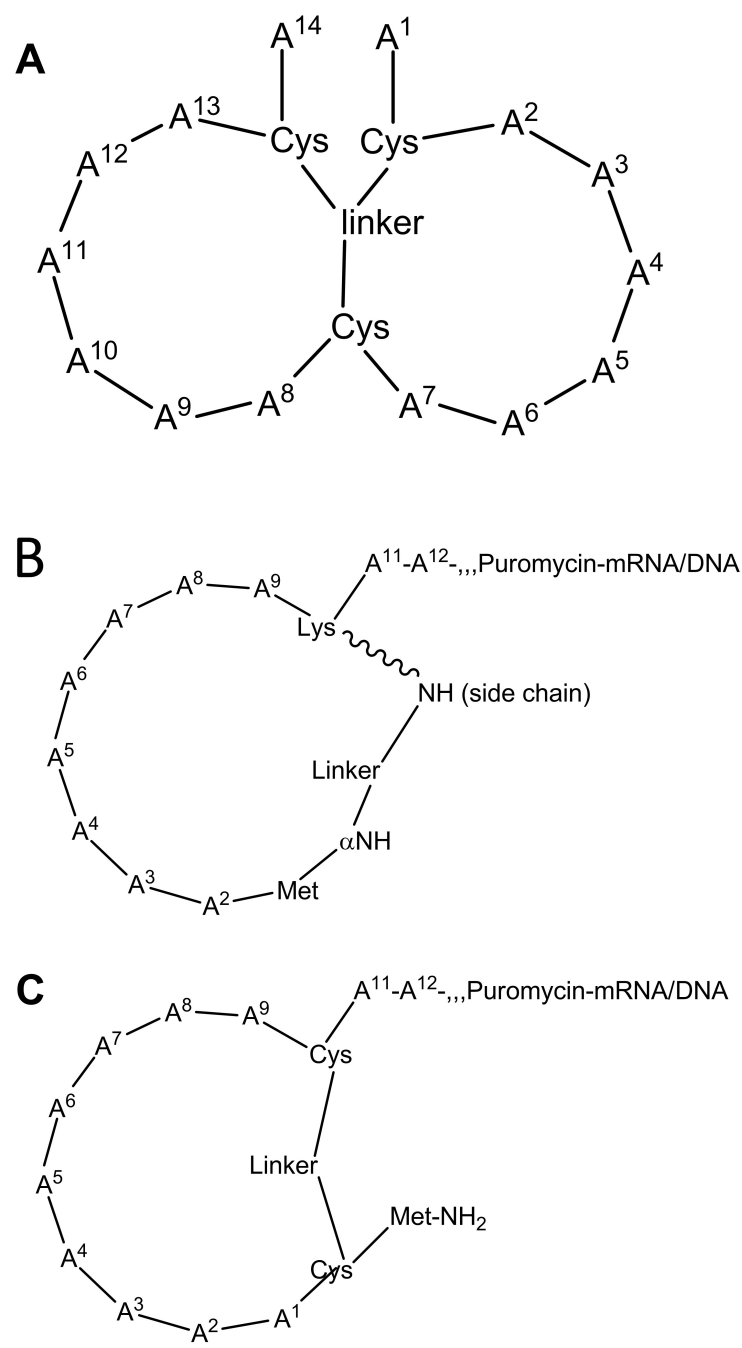

Fig. 2. Cyclic peptide libraries. (A) Bicyclic peptide with a chemical linker connecting three cysteine residues. (B) Cyclic peptide in mRNA display with a chemical linker coupling N-terminal Met with the side chain of Lys at position 10. (C) Cyclic peptide in mRNA display with a chemical linker connecting two cysteine residues.

a phage display library with four cysteine residues would allow a bicyclic peptide as seen in the structure of guanylin (Fig. 1). It remains to be determined whether this 4-Cys approach could be practical. As an alternative, a recent study reported the use of chemical linkers for the generation of bicyclic peptides (Heinis, 2011). The addition of cross-linkers to the phage display peptide relieves the burden of putting four cysteine residues in the sequence, and only three cysteine residues will suffice to form a bicyclic peptide (Fig. 2A). In addition, when the crosslinker connects three cysteine residues, the method of building the two-ring structure can be simplified. Implementing the phage display with a cross-linker technique, the Heinis group developed bicyclic peptides binding to protein molecules such as beta-catenin (Bertoldo et al., 2016) and Notch1 receptor (Urech-Varenne et al., 2015).

The use of different cross-linkers improved cyclic peptides based on mRNA display. As reviewed previously, the original cyclic peptides based on mRNA display (Fig. 2B) were pre- 
pared by coupling an $\mathrm{N}$-terminal Met residue with the side chain of a Lys residue at the C-terminal region of the peptides: two amino groups were linked together by a coupling reagent (Millward et al., 2007). While the original mRNA display only used ribosomal amino acids, a shrewd modification of mRNA display (Fig. 2C) led to the selection of an inhibitor of protease thrombin with nanomolar affinity (Schlippe et al., 2012). The modified mRNA display technique now includes unnatural amino acids as building blocks, and two cysteine residues are inserted in the sequence to allow a range of different crosslinkers.

\section{THE ROLE OF CYCLIC PEPTIDES IN THERAPEUTICS}

\section{Cyclic peptides in imaging and diagnostics}

Integrin binding affinity of peptides with RGD sequence has long been documented, and cyclic peptides containing RGD have been shown to inhibit tumor growth (Gehlsen et al., 1988). For example, cyclo-RGDfV (EMD 66203, f stands for D-Phe) could promote tumor regression by inhibiting angiogenesis (Storgard et al., 1999). However, the result of recent clinical trial with a cyclic RGD peptide, cilengitide showed that the peptide did not improve outcome when combined with chemotherapy (Stupp et al., 2014). While the cyclic RGD peptide may not be a promising drug lead, the ability to bind integrin $\alpha_{v} \beta_{3}$ makes it target solid tumor regions where angiogenesis is active, and the delivery of nanoparticles could be possible for either chemotherapy or cancer diagnosis. Monomeric cyclic RGD peptides (Beer et al., 2005), or multimeric RGD peptides (Liu et al., 2001) have been coupled to radioisotopes for diagnostic and therapeutic purposes. Efforts have been made to improve the tumor/background ratio, and several radio-

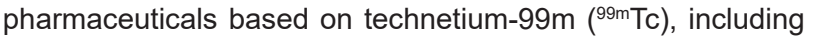
${ }_{99 m} T c-3 P-R G D_{2}$, are under clinical investigation for tumor imaging using positron emission tomography (Yan et al., 2015). Similarly, cyclic RGD peptide coupled iron oxide microparticles have been developed as contrast agent for imaging of angiogenic tumor using magnetic resonance (Melemenidis et al., 2015). In addition to cyclic RGD peptides, fluoresceinconjugated cyclic peptides show promise for tumor-targeted imaging (Shan, 2004), and a fibrin-binding cyclic peptide can be used for targeting thrombosis (Rezaeianpour et al., 2017). Overall, cyclic peptides are under development against several targets for use in imaging and diagnostics.

\section{Cyclization for better cell permeability and oral absorption}

Both linaclotide (2012) and plecanatide (2017) have been introduced since our previous review, and most of the cyclic peptides in clinical use are listed in Table 1. Linaclotide and plecanatide are mainly used to treat chronic idiopathic constipation. These drugs stimulate the cystic fibrosis transmembrane conductance regulator (CFTR) protein by activating guanylate cyclase. The stimulated CFTR releases anions, resulting in the secretion of positively charged ions and water molecules to the gut lumen, thereby exerting a stool softening effect. Since guanylin analogs work on the guanylate cyclase on the luminal surface of gut epithelial cells, oral administration allows them to reach their site of action with no need for cellular uptake.

With the exception of cyclosporine, the route of administration for cyclic peptides listed in Table 1 is either intravenous or topical, as their membrane permeability is poor. Cyclosporine is membrane permeable owing to hydrophilic portions embedded inside the molecule through several intramolecular hydrogen bonds. Cyclic peptides that are orally absorbed in mammals are reviewed elsewhere (Nielsen et al., 2017). It is known that simple cyclization does not make peptides membrane permeable (Kwon and Kodadek, 2007). However, cyclization still remains one of the strategies for improving membrane permeability. The basis for this approach is that cyclization provides the molecule with conformational rigidity and helical conformation. Hydrophobicity is also an important factor in determining cellular uptake, as demonstrated with $\mathrm{BH} 3$ peptide-based $\mathrm{Mcl}-1$ inhibitors (Muppidi et al., 2014). Muppidi and colleagues added a bisaryl cross-linker to $\mathrm{BH} 3$ peptide to improve cellular uptake and inhibitory activity. Importantly, the results showed the divergence of cellular uptake and in vitro activity of stapled peptides. The inhibitor activity was related to flexibility of the peptide, whereas the permeability was related to hydrophobicity. Designing inhibitors based simply on in vitro activity without considering cell permeability, may lead to loss of membrane permeability and affect availability of the inhibitor to the site of action.

Bicyclic peptides may also improve cell membrane permeability, compared to monocyclic peptides. The Pei group initially attempted to develop a cell-permeable cyclic peptide by inserting an arginine-rich cell-penetrating peptide sequence as a part of monocyclic peptide (Lian et al., 2014). While the simple insertion of cell-penetrating peptide did not improve

Table 1. Cyclic peptides in clinical use

\begin{tabular}{|c|c|c|c|}
\hline Name & Activity or indication & Route of administration & First clinical use \\
\hline Bacitracin & Antibiotic & Topical use & 1948 \\
\hline Vancomycin & Antibiotic & Injection & 1954 \\
\hline Colistin & Antibacterial against Gram (-) bacilli & Topical, injection & 1959 \\
\hline Dactinomycin, Actinomycin D & Anticancer & Injection & 1964 \\
\hline Cyclosporine & Immunosuppressant & Per oral, injection, topical & 1983 \\
\hline Eptifibatide & Antiplatelet & Injection only & 1998 \\
\hline Caspofungin & Antifungal & Injection & 2001 \\
\hline Ziconotide & Analgesic & Intrathecal injection & 2004 \\
\hline Anidulafungin & Antifungal & Injection & 2006 \\
\hline Linaclotide & Irritable bowel syndrome, chronic idiopathic constipation & Per oral & 2012 \\
\hline Plecanatide & Chronic idiopathic constipation & Per oral & 2017 \\
\hline
\end{tabular}


cell-permeability, bicyclization with the cross-linker greatly improved cell permeability. They were able to successfully deliver cyclic peptide inhibitors inside cells. Encouraged by their initial success, they screened a bicyclic peptide library for another cellular target, oncogenic K-Ras mutant protein. Protein-protein interactions were disrupted by low micromolar concentrations of the bicyclic peptide inhibitor selected from the screening (Trinh et al., 2016). This demonstrates the utility of cyclic peptides in disrupting protein-protein interactions inside cells, which has long been considered, a difficult if not impossible target.

Recently, Ohtsuki and coworkers screened cyclic peptide for cellular uptake (Yamaguchi et al., 2017). They screened a phage display cyclic peptide library for Caco-2 cell permeation, and the phage particle was considered a macromolecular drug delivered by the cyclic peptide. The selected cyclic peptide containing DNP sequence facilitated transcellular permeability of the phage particle. Cyclic peptides with transcellular permeability would be better than cell-penetrating peptide sequences, as they would be more stable and resistant to hydrolytic enzymes when administered orally.

\section{Receptor binding cyclic peptides}

Cell surface receptors are good targets for cyclic peptides. Compared to small molecules, cyclic peptides have more surface area that may be utilized for receptor binding. As cell surface receptors are displayed on the outside of the cell membrane, binding molecules need not cross the cell membrane. Binding affinity of cyclic RGD peptides toward integrin proteins has been described in the previous paragraph, and there are several other noteworthy examples. CJ-15,208 is a cyclic tetrapeptide with affinity to kappa opioid receptor, originally isolated from a fungal fermentation broth (Saito et al., 2002). A tryptophan isomer of this compound synthesized by the McLaughlin group showed stereospecific antagonism for the receptor both in vitro and in vivo, suggesting possible application in maintaining abstinence from psychostimulant abuse (Ross et al., 2012). Hruby and colleagues devised a cyclic peptide analog of melanocyte stimulating hormone (Cai et al., 2013). Cyclization with a thioether resulted in a potent antagonist $\left(\mathrm{IC}_{50}=17 \mathrm{nM}\right)$ against the human melanocortin 1 receptor. Their approach yielded a receptor antagonist in addition to improved metabolic stability. This peptide could be useful as a molecular probe for the diagnosis and treatment of skin cancer.

\section{Cyclic peptides as enzyme inhibitors}

The well-known immunosuppressant cyclosporine inhibits phosphatase activity of calcineurin. Either split-and-pool synthesis (Liu et al., 2010) or SICLOPPS technology (Naumann et al., 2008) has been used to develop cyclic peptide inhibitors and natural cyclic peptides, such as sunflower trypsin inhibitor-1 (sfti-1) (Colgrave et al., 2010). As reviewed previously, enzyme targets for cyclic peptide inhibitors are very diverse. To date, cyclic peptide inhibitors have been reported for protease, phosphatase, proteasome, HIV integrase, and dam methyltransferase, among others. A couple these of cyclic peptides inhibitors have notable functions. The first example is as contrast agent for positron emission tomography (PET) in tumor detection. The disulfide-containing cyclic peptide CTT (CTTHWGFTLC) was originally discovered as a matrix metalloproteinase inhibitor using a phage display technology (Koi- vunen et al., 1999). However, the original peptide was readily degraded in vivo. Wang and colleagues improved the stability of the peptide by removing the disulfide bond (Wang et al., 2009). Liu and colleagues conjugated the stable version of the CTT peptide to the chelator NOTA (1,4,7-triazacyclononanetriacetic acid) for labeling with ${ }^{68} \mathrm{Ga}$ (Liu et al., 2015). It is fascinating how the initial discovery of CTT eventually developed into a contrast agent for PET imaging. Another interesting target for cyclic peptide is dengue virus NS2b-NS3 protease. Dengue is a serious viral infection transmitted by mosquito bites, for which there exists no specific treatment. NS2b-NS3 protease is a good antiviral target, as it is required for viral maturation and infectivity (Lim et al., 2013). The Tambunan group used molecular docking to screen for cyclic peptide inhibitors of NS2b-NS3, assuming cyclization would increase stability (Tambunan and Alamudi, 2010). Similarly, a Chinese team led by Wang used a natural peptide library to screen for inhibitors of NS2b-NS3 (Xu et al., 2012). Interestingly, both laboratories could observe the benefit of cyclization in several aspects of inhibitors including specificity, stability, and cell membrane permeability. Their results showed that cyclization increased the inhibitory activity by more than tenfold $\left(\mathrm{K}_{\mathrm{i}} 42 \mathrm{vs}\right.$. $2.2 \mu \mathrm{M})$. Other systematic approaches to improve the specificity of NS3-NS2B have been performed; the results from these studies could be helpful for developing antivirals based on protease inhibition (Lin et al., 2017; Takagi et al., 2017).

\section{Cyclic peptides as protein-protein interaction inhibitors}

Protein-protein interaction have huge therapeutic potential,

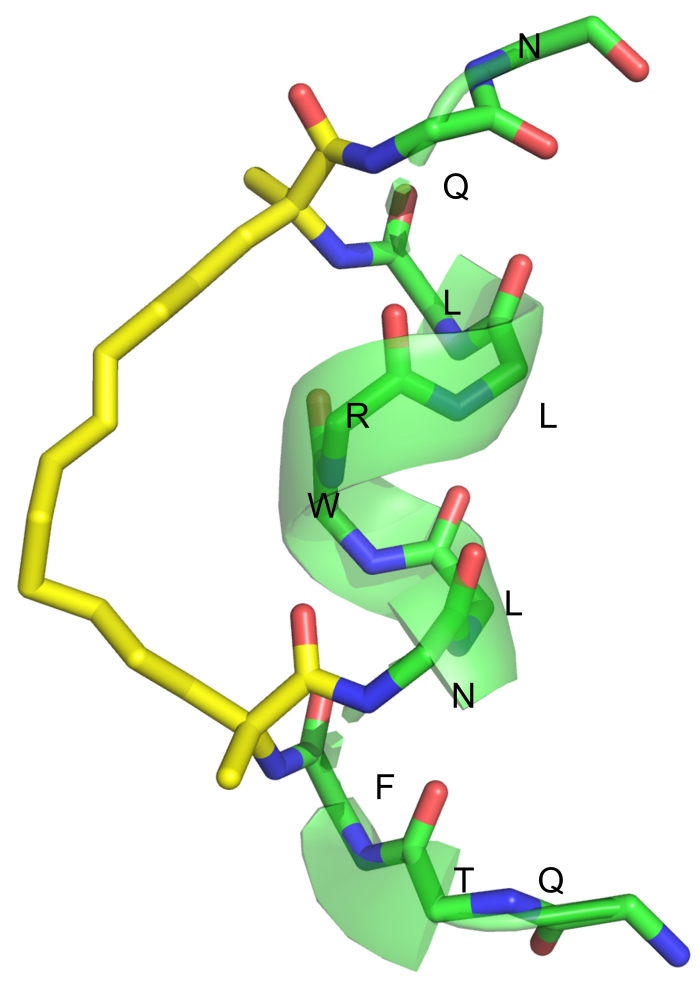

Fig. 3. Structure of SAH-p53-8, a stapled peptide. The aliphatic staple (yellow) provides conformational stability to the peptide sequence QTF*NLWRLL*QN (*indicates the aliphatic staple). The model was drawn from PDB id 3v3b. 
and usually a small molecule drug will bind to important areas deeper within the contact surface (Wells and McClendon, 2007). Peptides have a larger surface than small molecule inhibitors, and they can bind to the surface of target proteins. To develop cyclic peptides that perturb protein-protein interactions, phage display, combinatorial chemistry, synthetic approaches, and other genetic libraries such as SICLOPPS can be used. Bang and colleagues developed a peptide-peptoid hybrid molecule called a polo-like kinase inhibitor 1 by targeting the polo-box domain. They reported that cyclization through a thio-ether bridge dramatically improved binding affinity (Murugan et al., 2013). As described in an earlier section, stapled peptides are cyclic peptides prepared through crosslinking. Baek and colleagues reported a stapled p53 peptide, SAH-p53-8 (Fig. 3), that binds Mdm2 with high affinity. They reasoned that stapling provided conformational stability to the helical structure of the original p53 peptide (Baek et al., 2012). Similarly, Chang and coworkers developed a stapled peptide ASTP-7041 as a dual inhibitor of MDM2/MDMX. They observed that stapling the original linear peptide, obtained from phage display, yielded a more stable, cell penetrating, and specific inhibitor of MDM2/MDMX. ASTP-7041 showed tumor growth suppression in a xenograft cancer model (Chang et al., 2013). There are many examples showing that cyclization of peptides is able to improve the stability, cell membrane permeability, binding affinity and specificity. However, i peptide cyclization is not a panacea. The Tavassoli group screened for protein-protein interaction inhibitors using the SICLOPPS cyclic hexapeptide library. Their top 3 hits all contained stop codons, implying that linear peptides are the better for their target Bacillus anthracis protective antigen (Male et al., 2017).

\section{Cyclic peptides as RNA-protein interaction inhibitors}

As reviewed previously, cyclic peptides could be used to inhibit HIV-Tat transactivating response element (TAR) RNA, which is essential for viral replication (Lalonde et al., 2011). In addition, RNA-protein binding can be perturbed with cyclic peptides. Manna and colleagues synthesized a cyclic peptide that mimics the part of the La protein. It inhibits the viral translation of hepatitis C virus (Manna et al., 2013). GE23077, a cyclic peptide antibiotic that work on both Gram-negative and Gram-positive bacteria, inhibits the initiation of translation by disrupting the interaction between RNA polymerase and initiating nucleotides (Zhang et al., 2014). One cyclic peptide identified from the screening of split-intein circular ligation of peptides (SICLOP) does inhibit a virulence factor Hfq protein by blocking the Hfq-sRNA interaction (El-Mowafi et al., 2014). Ternatin is a natural cyclic peptide with cytotoxic effect. The Taunton group identified translation elongation factor-1A ternary complex as the molecular target of ternatin using a photo-affinity probe (Carelli et al., 2015). Jagtap and colleagues developed cyclic peptide inhibitor that modulates pre-mRNA splicing by targeting U2AF homology motifs (Jagtap et al., 2016). Overall, cyclic peptides can be used to disrupt RNAprotein interaction in diverse processes including translation initiation, elongation, pre-mRNA splicing, and viral replication.

\section{CONCLUSION}

Cyclic peptides have several structural features that make them good drug leads. Now, with the use of stapled peptides and bicyclic/tricyclic peptides, researchers are able to enhance the drug-like properties by reducing the flexibility of the molecule or by adding hydrophobicity. Novel phage display and combinatorial chemistry technology have transformed to take advantage of molecular dynamics and organic chemistry. These technologies have diversified the applications of cyclic peptides and more cyclic peptides are expected to emerge.

\section{ACKNOWLEDGMENTS}

This work was supported by research grants from Daegu Catholic University in 2017.

\section{REFERENCES}

Baek, S., Kutchukian, P. S., Verdine, G. L., Huber, R., Holak, T. A., Lee, K. W. and Popowicz, G. M. (2012) Structure of the stapled p53 peptide bound to Mdm2. J. Am. Chem. Soc. 134, 103-106.

Beer, A. J., Haubner, R., Goebel, M., Luderschmidt, S., Spilker, M. E., Wester, H. J., Weber, W. A. and Schwaiger, M. (2005) Biodistribution and pharmacokinetics of the alphavbeta3-selective tracer 18F-galacto-RGD in cancer patients. J. Nucl. Med. 46, 1333-1341.

Bertoldo, D., Khan, M. M., Dessen, P., Held, W., Huelsken, J. and Heinis, C. (2016) Phage selection of peptide macrocycles against beta-catenin to interfere with Wnt signaling. ChemMedChem 11, 834-839.

Cai, M., Stankova, M., Muthu, D., Mayorov, A., Yang, Z., Trivedi, D., Cabello, C. and Hruby, V. J. (2013) An unusual conformation of gamma-melanocyte-stimulating hormone analogues leads to a selective human melanocortin 1 receptor antagonist for targeting melanoma cells. Biochemistry 52, 752-764.

Carelli, J. D., Sethofer, S. G., Smith, G. A., Miller, H. R., Simard, J. L., Merrick, W. C., Jain, R. K., Ross, N. T. and Taunton, J. (2015) Ternatin and improved synthetic variants kill cancer cells by targeting the elongation factor-1A ternary complex. eLife 4, e10222.

Chang, Y. S., Graves, B., Guerlavais, V., Tovar, C., Packman, K., To, K. H., Olson, K. A., Kesavan, K., Gangurde, P., Mukherjee, A., Baker, T., Darlak, K., Elkin, C., Filipovic, Z., Qureshi, F. Z., Cai, H., Berry, P., Feyfant, E., Shi, X. E., Horstick, J., Annis, D. A., Manning, A. M., Fotouhi, N., Nash, H., Vassilev, L. T. and Sawyer, T. K. (2013) Stapled alpha-helical peptide drug development: a potent dual inhibitor of MDM2 and MDMX for p53-dependent cancer therapy. Proc. Natl. Acad. Sci. U.S.A. 110, E3445-E3454.

Colgrave, M. L., Korsinczky, M. J., Clark, R. J., Foley, F. and Craik, D. J. (2010) Sunflower trypsin inhibitor-1, proteolytic studies on a trypsin inhibitor peptide and its analogs. Biopolymers 94, 665-672.

Edman, P. (1959) Chemistry of amino acids and peptides. Annu. Rev. Biochem. 28, 69-96.

El-Mowafi, S. A., Alumasa, J. N., Ades, S. E. and Keiler, K. C. (2014) Cell-based assay to identify inhibitors of the Hfq-sRNA regulatory pathway. Antimicrob. Agents Chemother. 58, 5500-5509.

Fairlie, D. P. and Dantas de Araujo, A. (2016) Review stapling peptides using cysteine crosslinking. Biopolymers 106, 843-852.

Gehlsen, K. R., Argraves, W. S., Pierschbacher, M. D. and Ruoslahti, E. (1988) Inhibition of in vitro tumor cell invasion by Arg-Gly-Aspcontaining synthetic peptides. J. Cell Biol. 106, 925-930.

Heinis, C. (2011) Bicyclic peptide antagonists derived from genetically encoded combinatorial libraries. Chimia (Aarau) 65, 677-679.

Horton, D. A., Bourne, G. T. and Smythe, M. L. (2002) Exploring privileged structures: the combinatorial synthesis of cyclic peptides. J. Comput. Aided Mol. Des. 16, 415-430.

Jagtap, P. K., Garg, D., Kapp, T. G., Will, C. L., Demmer, O., Luhrmann, R., Kessler, H. and Sattler, M. (2016) Rational design of cyclic peptide inhibitors of U2AF homology motif (UHM) domains to modulate pre-mRNA splicing. J. Med. Chem. 59, 10190-10197.

Joo, S. H. (2012) Cyclic peptides as therapeutic agents and biochemical tools. Biomol. Ther. (Seoul) 20, 19-26. 
Koivunen, E., Arap, W., Valtanen, H., Rainisalo, A., Medina, O. P. Heikkila, P., Kantor, C., Gahmberg, C. G., Salo, T., Konttinen, Y. T., Sorsa, T., Ruoslahti, E. and Pasqualini, R. (1999) Tumor targeting with a selective gelatinase inhibitor. Nat. Biotechnol. 17, 768-774.

Kwon, Y. and Kodadek, T. (2007) Quantitative comparison of the relative cell permeability of cyclic and linear peptides. Chem. Biol. 14, 671-677.

Lalonde, M. S., Lobritz, M. A., Ratcliff, A., Chamanian, M., Athanassiou, Z., Tyagi, M., Wong, J., Robinson, J. A., Karn, J., Varani, G. and Arts, E. J. (2011) Inhibition of both HIV-1 reverse transcription and gene expression by a cyclic peptide that binds the Tat-transactivating response element (TAR) RNA. PLoS Pathog. 7, e1002038.

Lauber, T., Neudecker, P., Rosch, P. and Marx, U. C. (2003) Solution structure of human proguanylin: the role of a hormone prosequence. J. Biol. Chem. 278, 24118-24124.

Lian, W., Jiang, B., Qian, Z. and Pei, D. (2014) Cell-permeable bicyclic peptide inhibitors against intracellular proteins. J. Am. Chem. Soc. 136, 9830-9833.

Lim, S. P., Wang, Q. Y., Noble, C. G., Chen, Y. L., Dong, H., Zou, B., Yokokawa, F., Nilar, S., Smith, P., Beer, D., Lescar, J. and Shi, P. Y. (2013) Ten years of dengue drug discovery: progress and prospects. Antiviral Res. 100, 500-519.

Lin, K. H., Ali, A., Rusere, L., Soumana, D. I., Kurt Yilmaz, N. and Schiffer, C. A. (2017) Dengue virus NS2B/NS3 protease inhibitors exploiting the prime side. J. Virol. 91, e00045-17.

Liu, Q., Pan, D., Cheng, C., Zhang, A., Ma, C., Wang, L., Zhang, D., Liu, H., Jiang, H., Wang, T., Xu, Y., Yang, R., Chen, F., Yang, M. and Zuo, C. (2015) Targeting of MMP2 activity in malignant tumors with a $68 \mathrm{Ga}$-labeled gelatinase inhibitor cyclic peptide. Nucl. Med. Biol. 42, 939-944

Liu, S., Edwards, D. S., Ziegler, M. C., Harris, A. R., Hemingway, S. J. and Barrett, J. A. (2001) 99mTc-labeling of a hydrazinonicotinamide-conjugated vitronectin receptor antagonist useful for imaging tumors. Bioconjug. Chem. 12, 624-629.

Liu, T., Liu, Y., Kao, H. Y. and Pei, D. (2010) Membrane permeable cyclic peptidyl inhibitors against human Peptidylprolyl Isomerase Pin1. J. Med. Chem. 53, 2494-2501.

Male, A. L., Forafonov, F., Cuda, F., Zhang, G., Zheng, S., Oyston, P. C. F., Chen, P. R., Williamson, E. D. and Tavassoli, A. (2017) Targeting Bacillus anthracis toxicity with a genetically selected inhibitor of the PA/CMG2 protein-protein interaction. Sci. Rep. 7, 3104.

Manna, A. K., Kumar, A., Ray, U., Das, S., Basu, G. and Roy, S. (2013) A cyclic peptide mimic of an RNA recognition motif of human La protein is a potent inhibitor of hepatitis C virus. Antiviral Res. 97 223-226.

Melemenidis, S., Jefferson, A., Ruparelia, N., Akhtar, A. M., Xie, J., Allen, D., Hamilton, A., Larkin, J. R., Perez-Balderas, F., Smart, S. C., Muschel, R. J., Chen, X., Sibson, N. R. and Choudhury, R P. (2015) Molecular magnetic resonance imaging of angiogenesis in vivo using polyvalent cyclic RGD-iron oxide microparticle conjugates. Theranostics 5, 515-529.

Millward, S. W., Fiacco, S., Austin, R. J. and Roberts, R. W. (2007) Design of cyclic peptides that bind protein surfaces with antibody-like affinity. ACS Chem. Biol. 2, 625-634.

Muppidi, A., Doi, K., Ramil, C. P., Wang, H. G. and Lin, Q. (2014) Synthesis of cell-permeable stapled $\mathrm{BH} 3$ peptide-based $\mathrm{Mcl}-1$ inhibitors containing simple aryl and vinylaryl cross-linkers. Tetrahedron 70, 7740-7745

Murugan, R. N., Park, J. E., Lim, D., Ahn, M., Cheong, C., Kwon, T., Nam, K. Y., Choi, S. H., Kim, B. Y., Yoon, D. Y., Yaffe, M. B., Yu, D. Y., Lee, K. S. and Bang, J. K. (2013) Development of cyclic peptomer inhibitors targeting the polo-box domain of polo-like kinase 1. Bioorg. Med. Chem. 21, 2623-2634.

Naumann, T. A., Tavassoli, A. and Benkovic, S. J. (2008) Genetic selection of cyclic peptide Dam methyltransferase inhibitors. Chembiochem 9, 194-197.

Nielsen, D. S., Shepherd, N. E., Xu, W., Lucke, A. J., Stoermer, M. J. and Fairlie, D. P. (2017) Orally absorbed cyclic peptides. Chem. Rev. 117, 8094-8128.

O'Neil, K. T., Hoess, R. H., Jackson, S. A., Ramachandran, N. S., Mousa, S. A. and DeGrado, W. F. (1992) Identification of novel peptide antagonists for GPIIb/IIla from a conformationally constrained phage peptide library. Proteins 14, 509-515

Rezaeianpour, S., Bozorgi, A. H., Moghimi, A., Almasi, A., Balalaie, S., Ramezanpour, S., Nasoohi, S., Mazidi, S. M., Geramifar, P., Bitarafan-Rajabi, A. and Shahhosseini, S. (2017) Synthesis and biological evaluation of cyclic [99mTc]-HYNIC-CGPRPPC as a fibrin-binding peptide for molecular imaging of thrombosis and its comparison with [99mTc]-HYNIC-GPRPP. Mol. Imaging Biol. 19, 256-264.

Ross, N. C., Reilley, K. J., Murray, T. F., Aldrich, J. V. and McLaughlin, J. P. (2012) Novel opioid cyclic tetrapeptides: trp isomers of CJ15,208 exhibit distinct opioid receptor agonism and short-acting kappa opioid receptor antagonism. Br. J. Pharmacol. 165, 10971108.

Saito, T., Hirai, H., Kim, Y. J., Kojima, Y., Matsunaga, Y., Nishida, H., Sakakibara, T., Suga, O., Sujaku, T. and Kojima, N. (2002) CJ15,208 , a novel kappa opioid receptor antagonist from a fungus, Ctenomyces serratus ATCC15502. J. Antibiot. 55, 847-854.

Schlippe, Y. V., Hartman, M. C., Josephson, K. and Szostak, J. W. (2012) In vitro selection of highly modified cyclic peptides that act as tight binding inhibitors. J. Am. Chem. Soc. 134, 10469-10477.

Shan, L. (2004) Fluorescein-conjugated cyclic decapeptides, CGLIIQKNEC (CLT1) and CNAGESSKNC (CLT2). In Molecular Imaging and Contrast Agent Database (MICAD). Bethesda (MD).

Storgard, C. M., Stupack, D. G., Jonczyk, A., Goodman, S. L., Fox, R. I. and Cheresh, D. A. (1999) Decreased angiogenesis and arthritic disease in rabbits treated with an alphavbeta3 antagonist. J. Clin. Invest. 103, 47-54.

Stupp, R., Hegi, M. E., Gorlia, T., Erridge, S. C., Perry, J., Hong, Y. K., Aldape, K. D., Lhermitte, B., Pietsch, T., Grujicic, D., Steinbach, J. P., Wick, W., Tarnawski, R., Nam, D. H., Hau, P., Weyerbrock, A., Taphoorn, M. J., Shen, C. C., Rao, N., Thurzo, L., Herrlinger, U., Gupta, T., Kortmann, R. D., Adamska, K., McBain, C., Brandes, A. A., Tonn, J. C., Schnell, O., Wiegel, T., Kim, C. Y., Nabors, L. B., Reardon, D. A., van den Bent, M. J., Hicking, C., Markivskyy, A., Picard, M. and Weller, M.; European Organisation for Research and Treatment of Cancer (EORTC); Canadian Brain Tumor Consortium; CENTRIC study team (2014) Cilengitide combined with standard treatment for patients with newly diagnosed glioblastoma with methylated MGMT promoter (CENTRIC EORTC 26071-22072 study): a multicentre, randomised, open-label, phase 3 trial. Lancet Oncol. 15, 1100-1108.

Takagi, Y., Matsui, K., Nobori, H., Maeda, H., Sato, A., Kurosu, T., Orba, Y., Sawa, H., Hattori, K., Higashino, K., Numata, Y. and Yoshida, Y. (2017) Discovery of novel cyclic peptide inhibitors of dengue virus NS2B-NS3 protease with antiviral activity. Bioorg. Med. Chem. Lett. $27,3586-3590$.

Tambunan, U. S. and Alamudi, S. (2010) Designing cyclic peptide inhibitor of dengue virus NS3-NS2B protease by using molecular docking approach. Bioinformation 5, 250-254.

Trinh, T. B., Upadhyaya, P., Qian, Z. and Pei, D. (2016) Discovery of a direct ras inhibitor by screening a combinatorial library of cellpermeable bicyclic peptides. ACS Comb. Sci. 18, 75-85.

Urech-Varenne, C., Radtke, F. and Heinis, C. (2015) Phage selection of bicyclic peptide ligands of the notch1 receptor. ChemMedChem 10, 1754-1761.

Walensky, L. D., Kung, A. L., Escher, I., Malia, T. J., Barbuto, S., Wright, R. D., Wagner, G., Verdine, G. L. and Korsmeyer, S. J. (2004) Activation of apoptosis in vivo by a hydrocarbon-stapled BH3 helix. Science 305, 1466-1470.

Wang, W., Shao, R., Wu, Q., Ke, S., McMurray, J., Lang, F. F., Jr., Charnsangavej, C., Gelovani, J. G. and Li, C. (2009) Targeting gelatinases with a near-infrared fluorescent cyclic His-Try-Gly-Phe peptide. Mol. Imaging Biol. 11, 424-433.

Wells, J. A. and McClendon, C. L. (2007) Reaching for high-hanging fruit in drug discovery at protein-protein interfaces. Nature $\mathbf{4 5 0}$, 1001-1009.

Xu, S., Li, H., Shao, X., Fan, C., Ericksen, B., Liu, J., Chi, C. and Wang, C. (2012) Critical effect of peptide cyclization on the potency of peptide inhibitors against Dengue virus NS2B-NS3 protease. J. Med. Chem. 55, 6881-6887.

Yamaguchi, S., Ito, S., Kurogi-Hirayama, M. and Ohtsuki, S. (2017) Identification of cyclic peptides for facilitation of transcellular trans- 
port of phages across intestinal epithelium in vitro and in vivo. J. Control. Release 262, 232-238.

Yan, B., Quu, F., Ren, L., Dai, H., Fang, W., Zhu, H. and Wang, F. (2015) 99mTc-3P-RGD2 molecular imaging targeting integrin alphavbeta in head and neck squamous cancer xenograft. J. Radioanal. Nucl. Chem. 304, 1171-1177.
Zhang, Y., Degen, D., Ho, M. X., Sineva, E., Ebright, K. Y., Ebright, Y. W., Mekler, V., Vahedian-Movahed, H., Feng, Y., Yin, R., Tuske, S., Irschik, H., Jansen, R., Maffioli, S., Donadio, S., Arnold, E. and Ebright, R. H. (2014) GE23077 binds to the RNA polymerase ' $i$ ' and ' $i+1$ ' sites and prevents the binding of initiating nucleotides. elife 3, e02450. 